\title{
BITTE LIEBT ÖSTERREICH. CHRISTOPH SCHLINGENSIEF Y LA INMUNIDAD DEL ESPECTADOR
}

Data recepción: 2011/12/08

Data aceptación: 2012/07/26

Contacto autora: laura@laurafgibellini.com
Laura F. Gibellini

Universidad Complutense de Madrid School of Visual Arts, Nueva York

\section{RESUMEN}

Este artículo versa, a través del análisis de la acción vienesa Bitte Liebt Österreich de Christoph Schlingensief, sobre los dispositivos de inmunidad (nacional) que posibilitan la construcción de una mirada distanciada sobre el otro. Dicha mirada permitió, en la performance, activar una problemática capacidad de decisión sobre la vida (efectiva) del refugiado extranjero. Mediante una controvertida acción expandida en el espacio público, a modo de Gran Hermano, donde los límites entre lo auténtico y lo ficticio se diluyen, el autor alemán consiguió evidenciar los mecanismos de generación de la identidad nacional y del sentido de pertenencia del pueblo austríaco -y por analogía, de todos los demás.

Palabras Clave: inmunidad, mirada, espectáculo, esfera pública

\section{ABSTRACT}

In analysing Christoph Schlingensief's Viennese performance action Bitte Liebt Österreich, this article discusses the (national) immune mechanisms that construct a particular type of gaze that objectifies the 'Other'. Such a gaze imbues the Austrian people with the ability to decide on the (effective) lives of 'others', in this case, foreign refugees. Through a controversial performance in a public space (similar to the Big Brother), where the boundaries between real and fictional life have been diluted, the German author highlights the ways in which Austrian people (as well as other communities) generate their sense of belonging and their national identity.

Keywords: immunity, gaze, spectacle, public sphere

En verano del año 2000 se encargó al ya entonces controvertido Christoph Schlingensief una performance para el festival anual Wiener Festwochen de Viena. Como respuesta Schlingensief instaló, durante seis días, un contenedor de carga en la plaza Herbert von Karajan, al lado de la ópera. Doce personas identificadas como extranjeros que habían solicitado asilo político en Austria fueron invitadas a vivir en el contenedor.

Todo lo que ocurría dentro del container era retransmitido en directo por un canal televisivo en internet, a modo de un Gran Hermano muy particular. La audiencia podía votar diariamente y decidir los residentes que debían ser expulsados -a razón de dos al día. Sólo que la expulsión implicaba no sólo la salida del container, sino del país.

Al ganador se le prometió un premio en metálico y la posibilidad de adquirir el estatus de residente legal mediante el matrimonio con un ciudadano austríaco. Un gran cartel en el que se podía leer "Ausländer Raus!" ("¡Extranjeros Fuera!") coronaba el container, junto con el logo del Kronenzeitung -el tabloid más vendido en Austria- y banderas azules del populista partido de extrema derecha FPÖ -que desde las recientes elecciones formaba parte del gobierno de coalición. Mientras, el propio Schlingensief, altavoz en mano, instaba a los congregados en la plaza a participar en las votaciones. A su vez, 
fragmentos extraídos de la campaña política de Jörg Haider, el líder del FPÖ, podían escucharse en todo el lugar.

Las reacciones a Bitte liebt Österreich -Por favor, ama a Austria- (Fig. 1) no se hicieron esperar. Cientos de austríacos se congregaron en la plaza y unas ochocientas mil personas participaron en las votaciones. El día quince de junio cerca de seiscientos manifestantes, integrantes de las protestas semanales contra Haider y el FPÖ, atacaron el container y trataron de derribar el cartel antes mencionado. Mientras, el propio Haider y otros miembros del partido manifestaron su incomodidad con la acción de Schlingensief ${ }^{1}$-sin que quedara muy claro si la preocupación estaba causada por lo que podía identificarse como un guiño radical a su propia política nacional y xenófoba o por cuestiones relativas a la imagen pública (y turística) del país. Desde su instalación numerosas figuras públicas internacionales se habían acercado a interesarse por el proyecto y a conversar con el siempre presente artista -que se caracterizaba por su implicación directa y personal en sus acciones. Jörg Haider rechazó la entrevista organizada por Schlingensief con los habitantes del contenedor.

\section{La obra de Schlingensief}

Actuando como una suerte de maestro de ceremonias y de provocador mediático Schlingensief, conocido por sus provocativos filmes y performances teatrales ${ }^{2}$ y representante póstumo de Alemania en la 54 edición de la Bienal de

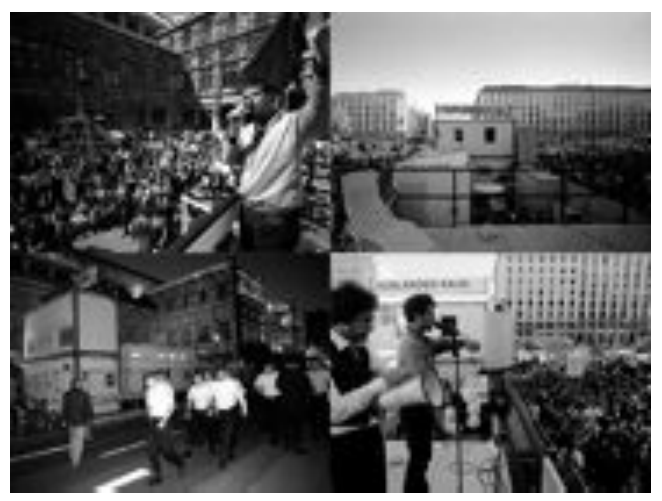

Fig. 1. Christoph Schlingensief, Bitte liebt Österreich, vistas del evento. Wiener Festwochen, Herbert Von Karajan Platz, Viena, 2000. Imágenes de David Baltzer.
Venecia (2011), ${ }^{3}$ crea en su obra un estado de inseguridad y de duda permanente donde se difuminan los límites entre la realidad y la ficción, el arte y el ataque (¿ofensivo?), la intención y la acción. Pero para Schlingensief más importante que la acción en sí es aquello que genera. De ahí su preocupación por transcender al espacio público y actuar directamente sobre él. En este caso se trataba de emitir una imagen 'sucia' de Austria ${ }^{4}$ con el fin no sólo de demostrar el contenido xenófobo de la política de Haider, sino de iluminar las reacciones enfrentadas entre alemanes y austríacos. Pero volveremos sobre ello más adelante.

Christoph Schlingensief inició su carrera en los años ochenta en la Alemania dividida. Cámara super 8 en mano e influido por una estética que estaba arraigando en la juventud del momento -basada en el gusto por lo feo, lo raro, lo oscuro, lo barato, la estética del do-it-yourself y lo violento- Schlingensief empezó a crear filmes en un ethos punk con estridentes pero intere-

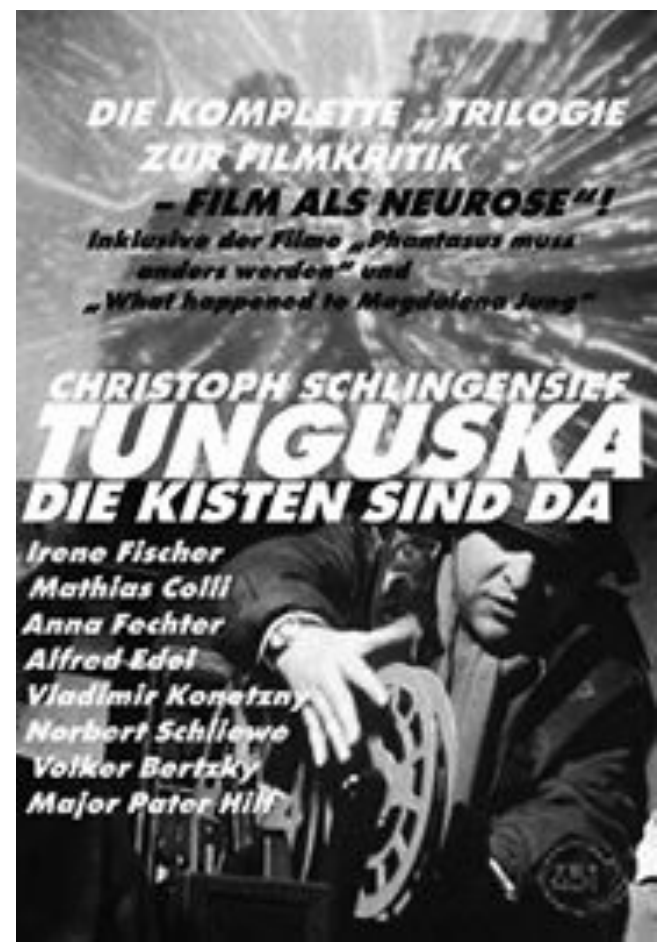

Fig. 2. Christoph Schlingensief, Tunguska, (Carátula del film), 71 min., 1984. 
santes resultados. En su primer largometraje, Tunguska (1984) (Fig. 2), juega con ideas fílmicas y antifílmicas para expresar una serie de nociones, no del todo linealmente racionales, sobre el desarrollo y la historia del cine alemán.

Con su introducción en el Volksbühne -centro de experimentación y caldo de cultivo de todo tipo de subculturas berlinesas en los años noventa- la estética 'trash' ${ }^{5}$ de Schlingensief fue evolucionando hacia revistas musicales satíricas cada vez más políticamente comprometidas.

A su vez comienza a difuminar los límites entre la vida real y lo escenificado. Por un lado, la necesidad de llegar a la seriedad del arte a través del uso ridículo y excesivo de mercancías y de bienes de consumo hace que éstas se multipliquen en escena. Por otro, Schlingensief introduce discapacitados y marginados en sus producciones, mediante los que apela a los estratos de la sociedad que carecen de lugar y aluden a problemáticas no resueltas de la comunidad. Finalmente su propia aparición en el teatro, donde actúa de 'sí mismo', diluirá su persona con el personaje que encarna en escena.

Considerado un provocador, criticado por todos los sectores políticos y sociales, Schlingensief no tomó nunca una postura política clara y unívoca. La confusión y la belleza del caos de las masas fue una parte integral de su estética y de su trabajo, en el que cada vez era más incierto lo que cada uno representaba -así cómo quién y qué era o no 'real'.

La expansión de los muros del teatro al espacio público, a la propia calle, y el uso de los media para incluir del modo más inmersivo posible a la esfera pública, le llevaron a implicarse y a aparecer en todos los medios imaginables -desde emisiones televisivas (tuvo su propio show) y radiofónicas en directo, hasta recurrentes apariciones en prensa. ${ }^{6}$

Tras su acción en Viena, Schlingensief se dirige más y más hacia el Gesamtkunstwerk, que culmina en sus producciones de Parsifal (Fig. 3) para el festival de teatro de Bayreuth a principios del año 2000, dejando atrás tácticas neo-vanguardistas disruptivas y el efectismo mass-mediático. La culminación de todo ello llegará en Mea Culpa. Ein ReadyMade Oper (2009), consi-

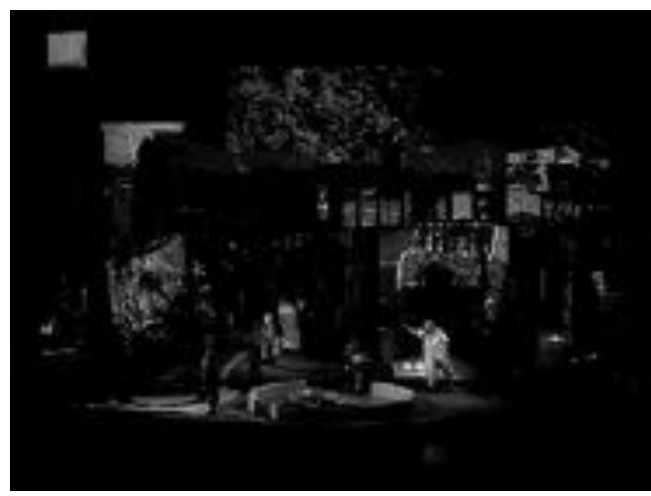

Fig. 3. Christoph Schlingensief, Parsifal, Bayreuth, agosto de 2007. Fotografía del Bayreuther Festspiele.

derada una de sus mejores piezas y para la que utilizó tecnología similar a la ya empleada en Bayreuth. Durante sus últimos años Schlingensief inició Operndorf Afrika (Fig. 4), un proyecto para crear una sala de ópera en un pueblo de Burkina Faso y que concibió como un proyecto social para reparar simbólicamente el daño infringido por Europa al continente africano.

Tras el fallecimiento del artista el pabellón alemán de la $54^{a}$ Bienal de Venecia -comisariado por Susanne Gaensheimer- albergó, en una atmósfera recargadamente solemne, algunas de las obras teatrales fundamentales del autor (Fig. 5).

Con su obra Schlingensief ha provocado la incomodidad propia de quien no ofrece una solución clara y única al problema de la producción artística en nuestra sociedad del bienestar. Efectivamente, para el artista el sentido que surge

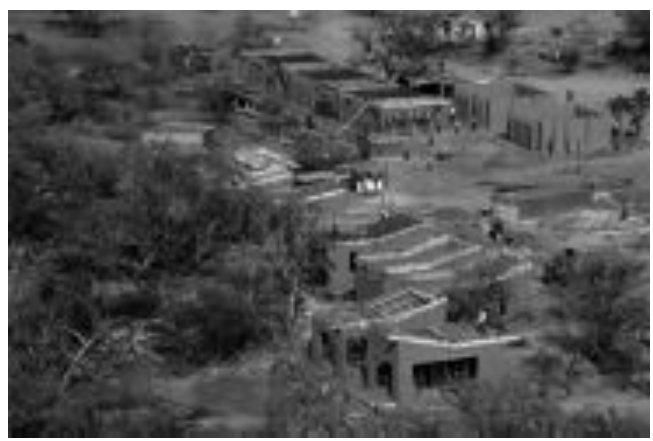

Fig. 4. Operndorf Afrika, Construcción del teatro en Burkina Faso, mayo 2011. Fotografía de Francis Kéré. 


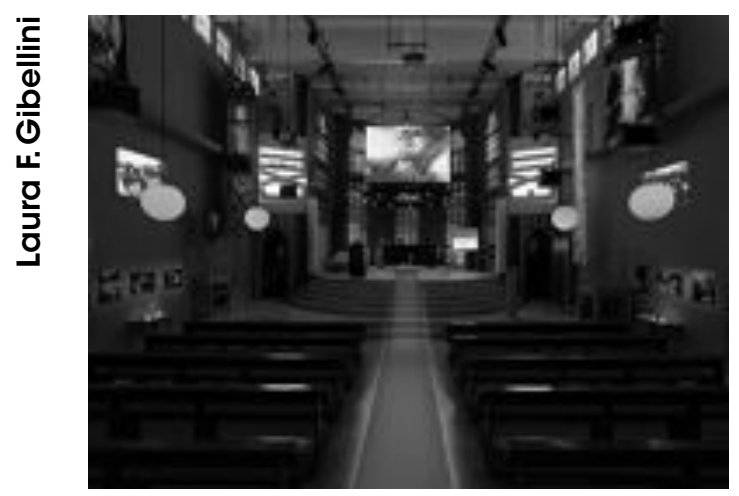

Fig. 5. Pabellón Alemán de la Bienal de Venecia, 4 de junio-27 de noviembre 2011. Fotografía de Roman Mensing, artdoc.de.

del caos es más relevante que del orquestado. Sus idas y venidas entre el aplomo de sus discursos y su desesperación ante sus despliegues de subjetividad (muchos le han acusado de ególatra) así como el rechazo de sus propios proyectos, no fueron fáciles de encajar.

En Bitte liebt Österreich Schlingensief recurrió a todo tipo de medios -la transmisión televisiva en directo, constantes apariciones en prensa, llamadas a la votación, una página web con una descripción, estereotípica, de los 'concursantes' (traducida al inglés, para maximizar su alcance)con el fin de transcender el escenario teatral e introducirse en el espacio público. ${ }^{7}$ Esto supuso un paso más allá en el drama literario basado en el lenguaje típico del teatro post-dramático de después de los años sesenta. ${ }^{8}$

Pero, a pesar de circunscribirse a toda una tradición teatral y presentarse en el marco del festival de teatro de Viena, nadie comprendió hasta qué punto todo estaba orquestado. ${ }^{9} \mathrm{En}$ una interesante conversación entre Peter Sloterdijk y Christoph Schlingensief ${ }^{10}$ el artista habla del carácter de hiper-realidad del evento. En respuesta a la afirmación de la prensa de que los 'refugiados' del contenedor eran actores, Schlingensief planteó qué inviste a éstos el estatus de actor -si es su actuación en el container o si cualquiera pasa a ser actor de su propia vida cuando ésta es retransmitida en directo- destacando así la importancia contextual de la acción. A su vez, el mero hecho de situar un container transparente (desde el punto de vista de la emisión televisiva total) no implica para Schlingensief au- tenticidad. Para él la 'verdad' esta en otro lugar, fuera de la escena.

\section{Wienaktion}

Desde mi punto de vista la confusión provocada por Schlingensief y la manifiesta duda de la veracidad de toda su operación evidencian y favorecen la irrupción de una mirada que no es concebida exclusivamente ya en relación a la visión, sino como modo de acceso fundamental al mundo -y de reorganización del conocimiento y de las prácticas sociales.

Surge así una mirada, distanciada y normalizadora, en el espectador de un espectáculo que considera con el desapego de quien, o bien no se identifica con lo que ve, o bien lo considera poco más que un show intranscendente, un simulacro incapaz de afectar su realidad. Ambos posicionamientos favorecen un estado de inmunidad que permite la identificación del otroextranjero fuera de uno, activando la 'perversa' capacidad en el observador austríaco de votar por la expulsión (¡del país!) de los 'concursantesinmigrantes' -sobre los que se aplican normas a las que el nacional es inmune.

Pero así mismo la reacción de repulsión por una parte de la población vienesa frente a un 'evento' a todas luces brutal, indica el rechazo a lo que consideran real: a saber, el juego con el destino de doce seres humanos y, quizá más relevante aún, la creación de una imagen racista del pueblo austríaco -que es impuesta sobre ellos no sólo por el extranjero (Schlingensief), alemán, sino por ellos mismos.

Es por causa de esta acepción inmunitaria, activada por la pertenencia o identidad nacional (y completamente asimilada en la organización social), por la que Schlingensief consiguió, con su acción, evidenciar la paradójica construcción de los estados-nación. Fue el resquebrajamiento de la identificación con una determinada imagen nacional como valor determinante y explicativo del sujeto, como imagen/verdad homogeneizante y que para algunos cristalizó en el contenedor de esta acción, lo que permitió los ataques de un amplio sector del pueblo austríaco.

Quizá por tanto no fuera el precario bienestar de los inmigrantes lo que suscitó tantas protes- 
tas, sino lo que se concibió como la imposición de una imagen xenófoba sobre toda Austria. Parece que todos los sectores político-sociales del país cayeron en la trampa del provocador artista alemán: la 'irritación total'11 -suscitada por la negación de la ilusión, una vida que imita al arte y a los media y un arte que interviene en la vida (y que conlleva una gran publicidad). ${ }^{12}$ Con la difusión de los límites entre lo imaginable y lo plausible y la visibilización de los desfavorecidos (los inmigrantes), Schlingensief arrojó luz sobre cuestiones éticas que se encuentran en la base de la creación identitaria de las comunidades nacionales.

\section{La inmunidad (nacional)}

En una mirada retrospectiva aparece más claro que la extraordinaria aportación del moderno Estado nacional ha sido la de disponer para la mayoría de sus habitantes una especie de vida familiar o de hogar: esa estructura imaginaria o real de inmunidad que pudo ser vivida como convergencia de lugar y sí-mismo o como identidad nacional (en el mejor sentido de la palabra). Donde más impresionantemente se produjo esa aportación fue alli donde se consiguió mejor la domesticación del Estado de poder en estado de bienestar. ${ }^{13}$

De acuerdo con Peter Sloterdijk la organización estatal nacional no es más que la generación de una suerte de receptáculo étnico de gruesas paredes -con un gran desnivel entre interior y exterior- ligado a un territorio, normalmente monolingüe y apoyado en símbolos y rituales redundantes que enfatizan su auto-certeza y que produce una estructura simbólica inmunitaria de seguridad. A finales del siglo XIX un gran número de movimientos populistas empezaron a desarrollarse, expandiendo las cuestiones nacionales del ámbito cultural al ámbito político. ${ }^{14}$ Con la modernización dicho despliegue inmunitario, centrado en folclores étnicos y rituales de tipo religioso o supersticioso, se fue transformando en todo tipo de tecnologías y representaciones exactas no sólo de seguridad, sino de certeza. ${ }^{15}$

Así la construcción de toda comunidad social obedece a una dialéctica en la que los sistemas de inclusión y de exclusión son promovidos por políticas de pertenencia. Mientras en las fronteras internas se trabaja para crear un modelo de pureza, en el exterior se enfatiza la diferenciación (y el peligro) no sólo racial, de clase, o político, sino también cultural. Esto sirve para justificar toda una serie de actividades encaminadas a la detección de las otredades -y así de los 'enemigos potenciales' dentro y fuera de los propios límites. El otro no es entonces un mero convecino sino que se torna un cúmulo de circunstancias externas que pueden ser o no bienvenidas.

Por otra parte, la política del miedo actual enmarca el lenguaje de la diferencia y el espectro de la integración social. ${ }^{16}$ Mientras, la inclusión del otro no supone la simple ampliación del radio de acción de una comunidad, sino la absorción de las fuerzas contrarias a ésta. La tendencia de exclusión general es así sustituida por juegos de rol basados en proyectos colectivos que no se destinan a la integración real del otro. Efectivamente a los inmigrantes se les deniega cualquier tipo de representación positiva, cualquier espacio de inscripción. ${ }^{17}$ Son percibidos a través de representaciones codificadas políticamente que los sitúan en una especie de margen sin imágenes -fuera de la imaginación social. Y de ahí a situarlos en un contenedor de carga y votar por su expulsión del país, hay un paso.

De esta forma los dispositivos de seguridad manifiestan una técnica política que se dirige tanto al medio concreto como a la probabilidad del acontecimiento, y suponen un nuevo paso en las técnicas de gobierno. A priori los mecanismos de seguridad anticipan la agresión y prevén el daño en una realidad concreta, pues no actúan sólo en el terreno de lo especulativo sino que conllevan la interacción controlada de los diferentes mecanismos activos que componen dicha realidad. ${ }^{18}$ Surge así un nexo casi espontáneo entre seguridad política e inmunidad (médica, natural, social o cultural) que los relaciona en términos de control y de ausencia de autonomía. Los sistemas inmunitarios de los cuerpos sociales se establecen de este modo como instrumentos de efectividad política que se vinculan con los mecanismos de seguridad puestos en marcha en términos de sujeción a una 'verdad/realidad' determinada, específica y local. 
Pero además el siglo XIX, que Foucault evidenció como el de la aparición de modos de poder asociados a nuevas formas de subjetividad en el contexto de radicales transformaciones sociales y económicas, supuso para Jonathan Crary ${ }^{19}$ una serie de cambios en la relación entre el cuerpo y las formas de poder institucional y discursivo que redefinieron el estatus del objeto observado, del observador y de toda la visión -preparando las condiciones para la llegada de un consumo espectacularizado de lo visible. El desarrollo de tecnologías para determinar la normalidad (o más bien para localizar y asignar una norma de comportamiento) en medicina, psicología y en las ciencias sociales, implicó la aparición del sujeto individual, haciéndolo visible. A su vez, el cuerpo es convertido en un lugar de poder y de verdad biopolítica, lo cual supone, entre otras muchas cosas, que lo que el ojo experimenta se concibe como una verdad. De este modo, con la relocalización de la visión en la subjetividad del observador, ésta adquiere una soberanía y autonomía sin precedentes -de la que deriva la estandarización y regulación de lo observado. Ello implica la aparición de nuevas formas de poder dependientes de la abstracción y normalización de la visión y, por tanto, de una nueva definición de "normalidad".

Y es la creación de una norma sobre lo otro, de una normalización activada por una mirada distanciada de lo inmune, la que permitió a los austríacos votar. Considerando, como lo hace Richard Sennet, ${ }^{20}$ que las imágenes de comunidad y solidaridad pública anteceden a todo contacto real y se purifican de los elementos diferenciadores y de conflicto con el fin de evitar el trato mutuo -y no para vincular a las personas entre sí- podemos concluir que la 'normalización' se basa en un intento de evitar la confrontación con el otro. Una vez más la distancia inmunitaria que rechaza el contacto actúa favoreciendo disposiciones que no implican la interacción (real).

\section{El discurso de verdad}

Desde mi punto de vista parte del interés de la acción de Schlingensief radica en su modo de poner en evidencia los mecanismos de generación de las imágenes comunitarias de los austríacos -así como de los alemanes (y, por ende, del resto de las naciones del mundo). Arraigadas en determinismos discursivos establecidos por generaciones, éstas incluyen lo que los demás conciben (y han concebido) que es uno.

Por su parte, si analizamos los términos de producción de la verdad como lo hace Rancière -argumentando como el lugar de ésta no es un ideal o un fundamento conceptual sino que "siempre es un topos, el lugar de una subjetivación en una trama argumentativa" ${ }^{21}$ veremos que se trata de un espacio real de negociación, una localización puntual dentro de un discurso históricamente determinado. Así, el lugar de cada verdad va más allá de su momento de generación y está caracterizado y condicionado por una dinámica argumental -que, sin embargo, puede (y ha de) ser renegociada.

La lógica de la emancipación y de la subjetivación política no es la mera afirmación de una particular identidad, sino el rechazo de toda identidad dada por otro -así como la posibilidad de renegociar cualquier devenir argumental. De este modo, la imagen identitaria dada por el otro alemán y que se proyectó en Bitte liebt Österreich fue rechazada por un amplio sector de la población vienesa (Fig. 6). Pero, a su vez, en la oposición y en la reacción violenta contra el contenedor de Schlingensief surgió una fisura. En la construcción de esa mirada hacia el otro que hemos venido argumentando (pero también en el rechazo a una determinada imagen nacional) se evidencia la imagen que los demás

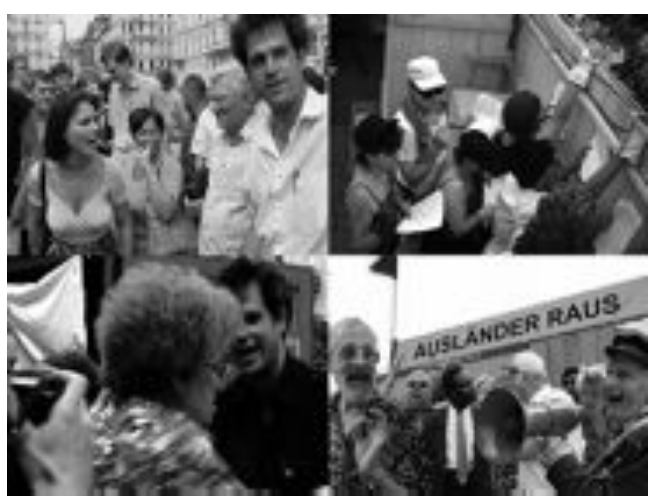

Fig. 6. Bitte liebt Österreich, Wiener Festwochen, Herbert Von Karajan Platz, Viena, 2000. Fotogramas del documental de Paul Poet Ausländer Raus! (Schlingensiefs Container), 2002. Imágenes de Paul Poet. 
tienen de uno -y no sólo la comprensión de uno mismo. Así, en la contestación de una supuesta valoración que el otro se ha formado de uno existe la concepción que uno mismo tiene de sí. Esta se genera en un efecto reflejo de lo que se cree que los otros piensan de uno. Por lo tanto, la reacción a una determinada imagen nacional, cultural o comunitaria no es una mera reacción contra su realidad inmediata, sino contra la figura que circula y que se ha construido en cada tradición que reacciona contra él. ${ }^{22}$

Lo que Schlingensief destapó con su contenedor fue más allá de un imaginario específico superpuesto a Austria -causado por la problemática política de inmigración del FPÖ. Con la acción se recreó un cuerpo de imágenes que apelaba al pasado reciente, turbulento e históricamente comprometido y arraigado tanto en la sociedad austríaca como en la alemana. Y, quizá más relevante aún, un pasado en que ambos se veían todavía reflejados.

Schlingensief, como es habitual en su trabajo, reclamaba aquí cuestiones éticas y de moralidad. Para el artista no se trataba de ironía sino del bien y del mal, de la verdad y la mentira ${ }^{23}$ en referencia al presente ( $\mathrm{y}$ al pasado) austríaco y alemán. La cuestión radicaba en puntualizar las fisuras de una identidad nacional paradójica, pero además en exponer y vincular, mediante su presencia física en el evento, al pueblo germano -y su propia responsabilidad ética y moral.

\section{El container}

Quisiera retomar aquí el contenido expandido de la acción del autor que, también para Sloterdijk, ${ }^{24}$ tuvo como objetivo tanto a los alemanes como a los austríacos y enfatizó problemáticas no resueltas en su pasado reciente. Me refiero, por supuesto, al pasado nazi (más allá de meramente xenófobo) de ambas naciones.

Si bien Austria fue anexionada por la Alemania nazi sin que los austríacos se consideraran a sí mismos responsables de su vinculación con el nacional socialismo, es sabido por todos que Hitler era austríaco, y que la anexión no tuvo lugar precisamente ante la 'impotencia' austríaca. Posteriormente, otro coqueteo con la derecha radical cuando Waldheim, antiguo miembro de la SA (organización paramilitar del partido nazi) fue presidente del país (entre 1986 y 1992), alertó a una traumatizada Alemania. Preocupada ésta por mostrarse lo suficientemente europea, ha venido sintiendo la necesidad de vigilar muy de cerca el ascenso de políticas derechistas en Austria -y en el resto del mundo. Con el acceso del FPÖ al gobierno se reavivaron así preocupaciones (traumáticas) muy arraigadas en la mentalidad del país germano.

Es evidente, pues, que quedaban muchos asuntos encubiertos en las relaciones entre ambos países cuando Schlingensief instaló su contenedor. Parte de la satisfacción del artista con su acción supuso haber expuesto el potencial de la política xenófoba de Haider en un contexto que transcendió el momento presente del verano del 2000, "facilitando la producción de imágenes sucias de Austria" de un modo tanto más efectivo cuanto que implicó la involucración de diversas instituciones oficiales del país. ${ }^{25}$

Se trataba finalmente de la escenificación de un lugar compartido, de un pasado turbulento que planteaba tanto una fisura -identitaria e inmunitaria- como el manejo de un daño. Por su parte, se abría así la posibilidad de reflexionar acerca de este lugar común, de la igualdad en la responsabilidad. Pero la igualdad, que se manifiesta en la medida en que es puesta a prueba, se ve doblemente cuestionada en la confrontación con el inmigrante del contenedor y con el otro alemán. Las barreras inmunológicas permitieron, una vez más, empujar una imagen propia de sí hacia el otro.

Parte de la relevancia de la acción de Schlingensief radica en cómo afectó a todos los sectores de la sociedad civil: la izquierda y la derecha. No por casualidad en las protestas contra el contenedor hubo gente que pidió la expulsión de los alemanes y la aceptación de los refugiados. ${ }^{26}$ Con ello, se manifestó una nueva reacción xenófoba-similar a la rechazada-contra un otro que sí parece adecuado mantener fuera del receptáculo propio -pues la otredad puede adquirir innumerables rostros.

Se demostró aquí cómo las fronteras inmunológicas seguían eminentemente activas y cómo la definición identitaria radica en neutralizar todo aquello que uno no admite de sí -y que es proyectado sobre el otro. En este proceso se 
desarrolla una mirada que adjudica una generación de 'verdad' distanciada sobre el mundo (sobre sí y sobre el otro) que no se genera sin embargo como proceso reflexivo sino que se extrae de un medio filtrado por la subjetividad de un espectador soberano, autónomo y autocentrado. Un ser inmunológicamente activo que descarta la ilusión de la escenificación, del teatro de Schlingensief y concibe lo que ve como verdad absoluta. Tal vez lo interesante sea reflexionar sobre las 'verdades' que se proyectaron aquel verano en Viena. Pero quizá más relevante sea pensar cómo afectó la acción a los austríacos y al propio artista -que, como ciudadano alemán, comparte una vinculación personal con lo expuesto.
Me pregunto si el proyecto reflexivo que supone la generación del yo (y que se ve afectado por las imágenes personales y comunitarias que se proyectan sobre él) y si la creciente 'responsabilidad' del individuo contemporáneo (planteada en el propio Schlingensief a través de su participación y que supone una toma de conciencia de sí) son capaces de resquebrajar las fronteras inmunitarias que favorecen a un espectador distanciado. Me pregunto si la propia implicación del artista alemán, si ese estar ahí e involucrarse con un cuerpo que no es sólo de observador, pudo crear alguna grieta productiva en las gruesas paredes ontológicas del ser nacional. Queda esperar que así fuera -y confiar en la capacidad del arte de transcender nuestra limitación efectiva y conceptual. 


\section{NOTAS}

${ }^{1}$ Denunciando el contenido ofensivo de los carteles instalados en el contenedor ["Ausländer Raus!" y otro que fue añadido con posterioridad en el que podría leerse "Unsere Ehre heißt Treue" ("Nuestro honor se llama lealtad"), un slogan de las SS prohibido en Alemania y supuestamente utilizado por el FPÖ durante su campaña electoral], pidieron que fueran retirados.

${ }^{2}$ Entre los filmes de Schlingensief destaca la "trilogía alemana" que realizó durante los años de la reunificación compuesta por: 100 Jahre Adolf Hitler. Die letzte Stunde im Führerbunker, 1989 (Cien años Adolf Hitler: Las últimas horas en el bunker del Führer); Das deutsche Kettensagen Massaker, 1990 (La masacre alemana de la motosierra); TERROR 2000. Intensivstation Deutschland, 1992 (TERROR 2000. Unidad de cuidados intensivos Alemania). En ellas se plantean diversos episodios de la historia alemana del siglo XX que se mueven entre la parodia y la estética gore. Entre sus performances teatrales se encuentran Operndorf Afrika (Festspielhaus Afrika), en proceso desde 2009; Via Intolleranza II, 2010; Remdoogo African Opera Village, 2009; Mea Culpa. Eine ReadyMade Oper, 2009; Church of Fear, 2008; To Burn Oneself With Oneself. The Romantic Damage Show, 2008.

En 1998 Schlingensief fundó "Chance 2000", un partido político con el que se presentó a las elecciones federales alemanas y en 1997, durante la documenta X, realizó Mein Filz, mein Fett, mein Hase. 48 Stunden Überleben für Deutschland (Mi fieltro, mi grasa, mi liebre. 48 horas de supervivencia por Alemania) una performance de cuarenta y ocho horas que incluía la acción Tötet Helmut Kohl (Mata a Helmut Kohl), que supuso la detención policial del artista. Para más información ver http://www.schlingensief.com

${ }^{3}$ Que le valió un tardío León de Oro al mejor pabellón nacional.

${ }^{4}$ Tal y como puede leerse en la entrevista al autor "Interview mit Schlingensief. Schmutzige Bilder" en Spiegel
Online la versión digital del periódico alemán el día 11 de junio de 2000. http://www.spiegel.de/kultur/gesellschaft/0,1518,80502,00.html. [Fecha de consulta: 13/11/2011].

${ }^{5}$ D. Diederichsen, "Epic Theater", Artforum, marzo 2011, pp. 232-239.

6 Para el artista el uso de los massmedia supone una forma de comunicación directa con el proletariado -que evita la exclusión burguesa que supone el lenguaje elitista de la esfera artística.

${ }^{7}$ Paul Poet, encargado de gestionar la retransmisión en la web del evento a través de webfreetv.com, presentó en el año 2002 el filme documental Ausländer Raus! (Schlingensiefs Container) realizado a partir del material filmado durante tan controvertida semana, y recoge los eventos desde múltiples perspectivas ofreciendo una interesante visión de los eventos. El documental fue recibido con gran éxito por parte de la crítica. Para más información http:// www. crippled. com/?cat=shop\&id $=125$ [Fecha de consulta: 12/11/2011]

${ }^{8}$ Para una argumentación extensiva sobre ello ver D. Varney, "Being Political in German Theatre and Performance: Anna Langhoff and Christoph Schlingensief" en Being There: After Proceedings of the 2006 Conference of the Australasian Association for Drama, Theatre and Performance Studies (I. Maxwell, Ed.), University of Sydney, Sidney, 2008.

${ }^{9} \mathrm{~T}$. Irmer, "Out with the Right!: Or, Let's Not Let Them in Again", Theater 32, 3, 2002, p. 63. Citado por D. Varney, ibid.

10 "Gespräch Zwischen Sloterdijk und Schlingensief zur Wienaktion" en http://www.schlingensief.com [Fecha de consulta: 20/09/2011].

${ }^{11} \mathrm{M}$. Löhndorf, "Totally Confusing Supposed Unambiguities", Kunstforum, vol. 142, octubre 1998, pp. 94101.

12 Es interesante seguir la prensa alemana de la época, sobretodo la versión online de Der Spiegel (aunque también Die Zeit) donde el seguimiento de la actividad de Schlingensief es espectacular
13 P. Sloterdijk, Esferas II. Globos. Macrosferología, Biblioteca de Ensayo, Siruela, Madrid, 2004, p. 864.

14 L. J. Vale, Architecture, Power and National Identity, Yale University Press, New Haven y Londres, 1992, p. 46 .

${ }^{15}$ P. Sloterdijk, En el mundo interior del capital. Para una teoría filosófica de la globalización, Biblioteca de Ensayo, Siruela, Madrid, 2007, p. 111

${ }^{16}$ H. K. Bhabha, El lugar de la cultura, Manantial, Buenos Aires, 2002.

$17 \mathrm{~N}$. Bourriaud, "Jens Haaning: Illegal Worker" en Hello, my Name is Jens Haaning (V. Pécoil, J. Haaning, Eds.), Le Presses du Réel, Dijon, 2003, pp. 103-104

${ }_{18}$ M. Foucault, Seguridad, territorio, población. Curso del Collège de France (1977-1978), Akal, Madrid, 2008, p. 59

19 J. Crary, Techniques of the Observer, The MIT Press, Cambridge Mass., 1991.

${ }^{20}$ Richard Sennet, Vida urbana e identidad personal, Península, Barcelona, 1975

21 J. Rancière, "Política, identificación y subjetivación" en $E$ l reverso de la diferencia: identidad y politica (B. Arditi, Ed.), Nueva Sociedad, Caracas, 2000, pp. 147

22 S. Žižek, Violence, Six Sideway Reflections, Big Ideas, Small Books, Picador, Nueva York, 2008.

${ }^{23}$ R. Koberg, trad. J. Riehle, Guggenheim Museum. Biography Schlingensief, Berlín, verano 1998. En www. schlingensief.com. [Fecha de consulta: 01/10/2011].

24 Ibid.

${ }^{25} \mathrm{~K}$. Weiss, "Recycling the Image of the Public Sphere in Art", Thresholds. Issue \#23: Deviant, 2002, pp. 58-64.

${ }^{26}$ En el film de Poet manifestantes exclaman "Ausländer rein, Piefkes raus!" (" ¡Extranjeros dentro, Piefkes fuera!"). Piefkes es un término peyorativo con el que los austríacos se refieren a los alemanes. 